\title{
FITODISPONIBILIDADE DE CÁDMIO, CHUMBO E CRÔMIO, EM SOJA CULTIVADA EM ARGISSOLO VERMELHO EUTRÓFICO A PARTIR DE ADUBOS COMERCIAIS
}

\section{PHYTOAVAILABILITY OF THE CADMIUM, LEAD AND CHROMIUM IN SOYBEAN CULTIVATED IN ARGISSOLO VERMELHO EUTRÓFICO, TREATED WITH COMMERCIAL FERTILIZERS}

\author{
Affonso Celso GONÇALVES Jr. ${ }^{1,2 *}$ \\ Antônio Carlos dos Santos PESSOA ${ }^{1 \dagger}$
}

\begin{abstract}
RESUMO
O objetivo deste trabalho foi avaliar a disponibilidade dos metais pesados tóxicos: cádmio, chumbo e crômio, em soja a partir de alguns adubos. Foram utilizados cinco adubos e sais solúveis contendo $\mathrm{Cd}, \mathrm{Pb}$ e Cr. Os tratamentos foram realizados em vasos de 2,5 L com aplicação de duas doses, 50 e $100 \mathrm{~kg} \mathrm{ha}^{-1}$ para os fertilizantes e 25 e $50 \mathrm{~kg} \mathrm{ha}^{-1}$ para os sais. O tecido vegetal de soja foi submetido à determinação de $\mathrm{Cd}, \mathrm{Pb}$ e $\mathrm{Cr}$, através de espectrometria de absorção atômica (chama). Para as plantas cultivadas no solo Pve, a maior liberação dos metais aconteceu nos seguintes tratamentos: para o $\mathrm{Cd}, \mathrm{CdCl}_{2} \cdot \mathrm{H}_{2} \mathrm{O} 2$, FTE Cerrado 2, Stimussed Plus e FTE Cerrado 1; para Pb, Zincogran 2, Micronutri $1212 \mathrm{e} \mathrm{1,}\left(\mathrm{CH}_{3} \mathrm{COO}\right)_{2} \mathrm{~Pb} .3 \mathrm{H}_{2} \mathrm{O} 2 \mathrm{e}$ FTE Cerrado $2 \mathrm{e}$ para $\mathrm{Cr}, \mathrm{CrCl}_{3} \cdot 6 \mathrm{H}_{2} \mathrm{O} 2 \mathrm{e} 1$ e Zincogran 2 e $1 . \mathrm{O}$ aumento da dosagem das aplicações dos fertilizantes e dos sais contendo os metais pesados tóxicos favoreceram o aumento da concentração dos metais nas plantas.

Palavras-chave: soja; metais pesados; adubos.
\end{abstract}

\section{SUMMARY}

The aim of this work was to evaluate the availability of the toxic heavy metals: cadmium, lead and chromium, in soybean, from some fertilizers. Five fertilizers and soluble salts contend $\mathrm{Cd}, \mathrm{Pb}$ and $\mathrm{Cr}$ were used. All the treatments were accomplished in vases of $2,5 \mathrm{~L}$ with application of two doses, 50 and $100 \mathrm{~kg} \mathrm{ha}$ ${ }^{1}$ for the fertilizers and 25 and $50 \mathrm{~kg} \mathrm{ha}^{-1}$ for the salts. The vegetable tissue of soybean was submitted to the analysis of $\mathrm{Cd}, \mathrm{Pb}$ and $\mathrm{Cr}$, by atomic absorption spectrometry (flame). In the plants cultivated in the soil Pve, the largest release of the metals occurred in the following treatments: for the $\mathrm{Cd}, \mathrm{CdCl}_{2} . \mathrm{H}_{2} \mathrm{O} 2, \mathrm{FTE}$ Cerrado 2 , Stimussed Plus and FTE Cerrado 1; for Pb, Zincogran 2, Micronutri 1212 and 1, $\left(\mathrm{CH}_{3} \mathrm{COO}\right)_{2} \mathrm{~Pb} .3 \mathrm{H}_{2} \mathrm{O} 2$ and FTE Cerrado 2 and for $\mathrm{Cr}, \mathrm{CrCl}_{3} \cdot 6 \mathrm{H}_{2} \mathrm{O} 2$ and 1 and Zincogran 2 and 1 . The increase of the dosage of the applications of the fertilizers and of the salts contentaining the toxic heavy metals favored the increase of the concentration of the metals in the plants.

Key-words: soybean; heavy metals; fertilizers.

\footnotetext{
${ }^{1}$ Professor do Centro de Ciências Agrárias da UNIOESTE, Rua Pernambuco, 1777 CEP 85960-000, Marechal Cândido Rondon - PR. * Author for correspondence, e-mail: affonso@unioeste.br.

${ }^{2}$ Grupo de Estudos em Solos e Meio Ambiente - GESOMA, Laboratório de Química Agrícola e Ambiental, UNIOESTE, Marechal Cândido Rondon PR.

${ }^{\dagger}$ (in memorian).
} 
GONÇALVES Jr., A.C. e PESSOA, A.C.S. Fitodisponibilidade de cádmio...

\section{INTRODUÇÃO}

A deficiência de micronutrientes nos solos agrícolas representa uma preocupação crescente, com tendência a se acentuar num futuro próximo. O cultivo em solos de baixa fertilidade, a calagem e o aumento da produtividade, são fatores que têm favorecido o aumento das deficiências de micronutrientes (1).

Os adubos utilizados para suprir micronutrientes possuem uma composição, que além dos elementos desejáveis, também, em geral, contém metais pesados tóxicos, como cádmio, chumbo e o crômio.

A expressão "metal pesado" se aplica a elementos que tem peso específico maior que $5 \mathrm{~g} \mathrm{~cm}^{-3}$ ou que possuem número atômico maior que 20 (2).

Entre os micronutrientes aparecem vários metais pesados que são classificados como essenciais $(\mathrm{Cu}, \mathrm{Fe}, \mathrm{Mn}, \mathrm{Mo}$ e $\mathrm{Zn})$, sendo indispensáveis para o desenvolvimento das plantas; benéficos ( $\mathrm{Co}, \mathrm{Ni}$ e $\mathrm{V})$, que colaboram com o desenvolvimento das plantas, mas sua falta não é considerada um fator limitante e não essenciais ou tóxicos: $(\mathrm{Cd}, \mathrm{Cr}, \mathrm{Hg}, \mathrm{Pb})$, sendo prejudiciais às plantas (3).

$\mathrm{O}$ aumento acentuado das concentrações de metais pesados nos solos de agricultura altamente tecnificada é resultado da deposição atmosférica e da aplicação de agrotóxicos, resíduos orgânicos e inorgânicos, urbanos e industriais, fertilizantes e corretivos (4-5-6).

A dinâmica de um elemento no sistema soloplanta-atmosfera deve ser acompanhada e medida pelas seguintes variáveis: diminuição no crescimento ou redução na colheita, sintomas visíveis e concentração no tecido (7-8).

Este trabalho objetivou avaliar a fitodisponibilidade dos metais pesados tóxicos cádmio, chumbo e crômio na cultura de soja (Glycine max (L) Merril), cultivada num solo de textura argilosa, argissolo vermelho eutrófico (PVe), com aplicações de alguns adubos comerciais.

\section{MATERIAL E MÉTODOS}

\section{Coleta e Preparo dos Solos}

Utilizou-se como matriz, o argissolo vermelho eutrófico (PVe) (9). Retiraram-se as amostras de solo, da camada arável $(0-20 \mathrm{~cm})$ que foram secas ao ar, e, logo após, passadas em peneira de $4 \mathrm{~mm}$. O solo foi coletado no Campus da Universidade Estadual de Maringá, Maringá-PR.

\section{Análises Preliminares}

\section{Análises químicas e físicas dos solos e adubos}

Efetuaram-se análises químicas para fins de fertilidade e análises físicas para determinação granulométrica, no laboratório de análise de rotina do Departamento de Agronomia da Universidade Estadual de Maringá (10-12). Os resultados encontramse na Tabela 1.

A análise dos adubos e dos solos para determinação total da concentração dos metais pesados tóxicos, cádmio $(\mathrm{Cd})$, chumbo $(\mathrm{Pb})$ e crômio $(\mathrm{Cr})$, foi realizada através de digestão nitro-perclórica (10) e os metais determinados seguindo-se técnicas de Espectrometria de Absorção Atômica, modalidade chama (11). Os resultados encontram-se nas Tabelas 2 e 3 , respectivamente.

TABELA 1 - Caracterização química e granulométrica do solo (PVe).

\begin{tabular}{|c|c|c|c|c|c|c|c|c|c|c|}
\hline $\mathrm{Ph}$ & $\mathrm{Al}^{3+}$ & $\mathrm{H}^{+}+\mathrm{Al}^{3+}$ & $\mathrm{Ca}$ & $\mathrm{Mg}$ & K & $\mathrm{P}$ & C & Areia & Silte & Argila \\
\hline$\left(\mathrm{CaCl}_{2}\right)$ & \multicolumn{5}{|c|}{$\left(\mathrm{mmol}_{\mathrm{c}} \mathrm{dm}^{-3}\right)$} & $\left(\mathrm{mg} \mathrm{dm}^{-3}\right.$ & $\left(\mathrm{g} \mathrm{dm}^{-3}\right)$ & & $(\%)$ & \\
\hline 5,1 & 0,00 & 49,6 & 62,0 & 18,2 & 5,3 & 3,0 & 22 & 21 & 27 & 52 \\
\hline
\end{tabular}

$\mathrm{pH}$ em $\mathrm{CaCl}_{2} 0,01 \mathrm{~mol} \mathrm{~L}^{-1}$;

Extrator de Fósforo Mehlich-1

TABELA 2 - Concentrações de cádmio, chumbo e crômio nos adubos.

\begin{tabular}{lccc}
\hline \multicolumn{1}{c}{ Adubo } & Cádmio & Chumbo $\left(\mathrm{mg} \mathrm{kg}^{-1}\right)$ & Crômio \\
\hline Stimussed Plus & 4,0 & 1623 & 6500 \\
BR-12 Especial & 164 & 6132 & 104 \\
FTE-Cerrado & 323 & 1713 & 169 \\
Zincogran & 99 & 1464 & 1111 \\
Micronutri 121 & 10,8 & 1960 & 292 \\
\hline
\end{tabular}


GONÇALVES Jr., A.C. e PESSOA, A.C.S. Fitodisponibilidade de cádmio...

TABELA 3 - Concentrações de cádmio, chumbo e crômio no solo PVe.

\begin{tabular}{|c|c|c|c|}
\hline Solo & Cádmio & Chumbo & Crônio \\
\hline Pve & $0,00^{*}$ & 8,13 & 51,38 \\
\hline
\end{tabular}

Valor de concentração abaixo do limite de detecção do método. Metodologia de extração segundo EPA's Sampling and analysis methods. Determinação por espectrometria de absorção atômica-chama.

\section{Instalação e Condução do Experimento em Casa de Vegetação}

\section{Adubação e calagem}

A adubação foi feita através da interpretação da análise química do solo e necessidade da cultur (12-13), com nitrogênio e fósforo na forma de $\left(\mathrm{NH}_{4}\right)\left(\mathrm{H}_{2} \mathrm{PO}_{4}\right)$ p.a., e potássio na forma de $\mathrm{KCl}$ p.a.. $\mathrm{A}$ adubação de cobertura com sulfato de amônio foi realizada aos vinte e oito dias após a germinação.

A correção da acidez do solo foi feita utilizando $\mathrm{CaCO}_{3}$ e $\mathrm{MgCO}_{3}$, reagentes p.a. na proporção de $3: 1, \mathrm{Ca} / \mathrm{Mg}$ em quantidades equivalentes ao $\mathrm{CaCO}_{3}$ encontrados na curva de calibração. A quantidade de calcário aplicada no solo foi de $2 \mathrm{t} \mathrm{ha}^{-1}$, visando elevar o $\mathrm{pH}$ do solo para aproximadamente 6,0 .

\section{Tratamentos}

Após a adubação e calagem, os solos foram acondicionados em vasos de PVC de 2,5 L. Foram utilizados cinco adubos: Stimussed Plus, BR-12 Especial, FTE-Cerrado, Zincogran e Micronutri 121.

$O$ adubo Stimussed Plus foi aplicado na semente, na ordem de $0,2 \mathrm{~kg} \mathrm{ha}^{-1}$ conforme recomendação do fabricante. Os adubos BR-12 Especial, FTECerrado, Zincogran e Micronutri 121 foram adicionados em dosagens de 50 e $100 \mathrm{~kg} \mathrm{ha}^{-1}$, sendo o cálculo efetuado em cima do volume de solo utilizado em cada vaso $\left(2,5 \mathrm{dm}^{3}\right)$. Os tratamentos testemunhas constaram de solo apenas.

Os adubos utilizados neste experimento estão sendo aplicados em grandes quantidades atualmente sendo fontes de cobre, zinco, ferro, manganês, entre outros micronutrientes essenciais e benéficos. As doses aplicadas foram a recomendada $\left(50 \mathrm{~kg} \mathrm{ha}^{-1}\right) \mathrm{e}$ o dobro (100 kg ha-1).

Também foram aplicados no solo, na forma de solução aquosa: sais de cádmio e crômio na forma de cloreto e chumbo na forma de acetato, nas dosagens de 25 e $50 \mathrm{~kg} \mathrm{ha}^{-1}$ do metal para os tratamentos 1 e 2 respectivamente. Estes sais foram aplicados na forma de solução aquosa antes da semeadura.

\section{Plantio e coleta do material vegetal}

Cada vaso recebeu oito sementes de soja. Após a germinação das sementes, foi feito um desbaste deixando-se apenas seis plantas por vaso, por um período de quarenta dias. Após este período, a parte aérea das plantas foi coletada e seca em estufa a $65^{\circ} \mathrm{C}$ até peso constante, evitando-se perdas e contaminação.

\section{Determinação dos Metais Pesados Tóxicos $\mathrm{Cd}, \mathrm{Pb}$ e Cr no Material Vegetal}

Para a determinação dos teores de $\mathrm{Cd}, \mathrm{Pb}$ e $\mathrm{Cr}$ nas plantas, utilizou-se digestão nitro-perclórica (10). As determinações dos metais pesados nos extratos seguiram técnicas de espectrometria de absorção atômica, modalidade chama (11).

\section{Análise Estatística e Delineamento Experimental}

Para analisar estatisticamente os resultados obtidos, utilizou-se o Teste Tukey a $5 \%$ (14).

O delineamento experimental foi inteiramente casualizado em esquema fatorial $2 \times 6 \times 3$ ( 2 solos, 6 fertilizantes e 3 tratamentos de metais pesados tóxicos), com 3 repetições.

\section{RESULTADOS E DISCUSSÃO}

Em relação aos tratamentos, o que mais disponibilizou cádmio para a parte aérea das plantas de soja foi o tratamento com $\mathrm{CdCl}_{2} . \mathrm{H}_{2} \mathrm{O}\left(50 \mathrm{~kg} \mathrm{ha}^{-1}\right)$ embora, pelo teste de Tukey a $5 \%$, não tenha se diferenciado dos tratamentos: FTE Cerrado (50 e $100 \mathrm{~kg}$ ha $^{-1}$ ) e Stimussed Plus (Tabela 4).

Entre os tratamentos que não disponibilizaram cádmio para as plantas, pelo teste de Tukey a $5 \%$, podemos destacar os tratamentos com os adubos: Micronutri 121 (50 e $100 \mathrm{~kg} \mathrm{ha}^{-1}$ ) e Zincogran (50 kg $\mathrm{ha}^{-1}$ ), embora não tenham se diferenciado estatisticamente a $5 \%$ dos tratamentos onde houve uma menor disponibilização do metal, como Br-12 Especial (50 e $\left.100 \mathrm{~kg} \mathrm{ha}^{-1}\right)$, Zincogran (100 $\left.\mathrm{kg} \mathrm{ha}^{-1}\right)$ e testemunhas.

Os resultados obtidos por Gonçalves Jr. et al. (2000), mostram que a concentração de cádmio proveniente de adubos comerciais, presente na parte aérea das plantas de soja cultivada num solo arenoso, é mais alta que os valores obtidos neste experimento. Isto pode ser explicado pela maior CTC dos solos argilosos, caso do solo PVe, tornando este elemento menos disponível para as plantas, além do que, a energia de ligação para o cádmio é maior em solos que apresentam maiores teores de argila (15-16).

Segundo Baker e Chesnin (18), teores acima de $0,2 \mathrm{mg} \mathrm{kg}^{-1}$ de cádmio nas plantas já são conside- 
rados tóxicos e prejudiciais ao seu desenvolvimento. Neste trabalho, não foram observados altos teores de cádmio.

As concentrações de chumbo encontradas no tecido vegetal de soja mostram que houve uma absorção significativa deste metal pelas plantas a partir dos adubos aplicados. Para as plantas testemunhas, a concentração média encontrada foi de $0,250 \mathrm{mg}$ $\mathrm{kg}^{-1}$, mostrando que a presença deste metal no solo (Tabela 3) foi o fator responsável pela disponibilização para a planta (Tabela 4).

Os adubos Zincogran (100 kg ha $\left.{ }^{-1}\right)$, Micronutri 121 (50 e $\left.100 \mathrm{~kg} \mathrm{ha}^{-1}\right),\left(\mathrm{CH}_{3} \mathrm{COO}\right)_{2} \mathrm{~Pb} .3 \mathrm{H}_{2} \mathrm{O}$ (50 kg ha$\left.{ }^{1}\right)$ e FTE Cerrado $\left(100 \mathrm{~kg} \mathrm{ha}^{-1}\right)$, foram os que disponibilizaram a maior concentração do metal para o tecido vegetal da soja (Tabela 4).

Os teores de chumbo na folha, acima de 1,0 $\mathrm{mg} \mathrm{kg}{ }^{-1}$, são considerados tóxicos para a soja (17). Pelos resultados obtidos neste trabalho, pode-se afirmar que a maioria dos adubos utilizados liberou teores acima do limite considerado adequado.

Os resultados obtidos na determinação de crômio no tecido vegetal de soja revelaram que em todos os tratamentos, inclusive na testemunha, hou- ve absorção do metal pela planta.

A concentração média encontrada na testemunha foi de $1,170 \mathrm{mg} \mathrm{kg}^{-1}$, sendo assim, observa-se que para o caso do crômio, o próprio solo contribuiu para a liberação do metal para as plantas, o que pode ser explicado pela grande concentração do elemento no solo (Tabela 3), em relação ao cádmio e o chumbo.

Os resultados obtidos para os tratamentos mostram que houve uma maior disponibilização de crômio para as plantas de soja nos tratamentos com $\mathrm{CrCl}_{3} \cdot 6 \mathrm{H}_{2} \mathrm{O}\left(25\right.$ e $\left.50 \mathrm{~kg} \mathrm{ha}^{-1}\right)$, os adubos Zincogran $\left(50\right.$ e $\left.100 \mathrm{~kg} \mathrm{ha}^{-1}\right)$ e Micronutri $121\left(100 \mathrm{~kg} \mathrm{ha}^{-1}\right)(\mathrm{Ta}-$ bela 4$)$.

Os tratamentos que menos disponibilizaram o metal para as plantas cultivadas neste solo, foram: FTE Cerrado (100 kg ha-1), Stimussed Plus, testemunha, BR-12 Especial (50 e $\left.100 \mathrm{~kg} \mathrm{ha}^{-1}\right)$, Micronutri $121\left(50 \mathrm{~kg} \mathrm{ha}^{-1}\right)$ e FTE Cerrado (50 kg ha-1), não apresentando diferenças significativas entre si (Tabela 4).

Os teores de crômio considerados fitotóxicos para a maioria das culturas são acima de $0,5 \mathrm{mg} \mathrm{kg}^{-1}$ (18). Pelos resultados obtidos neste trabalho, podese afirmar que em todos os tratamentos este valor foi ultrapassado.

TABELA 4 - Tratamentos, doses e médias das concentrações de Cd, $\mathrm{Pb}$ e $\mathrm{Cr}$ na parte aérea das plantas de soja (médias de 3 repetições).

\begin{tabular}{|c|c|c|c|c|}
\hline Tratamentos/adubos & Doses & $\mathrm{Cd}$ & $\mathrm{Pb}$ & $\mathrm{Cr}$ \\
\hline & \multicolumn{2}{|c|}{$\mathrm{Kg} \mathrm{ha}^{-1}$} & \multicolumn{2}{|c|}{$\mathrm{mg} \mathrm{kg}^{-1}$} \\
\hline Testemunhas & 0,0 & $0,017 c$ & $0,250 d$ & $1,167 b$ \\
\hline Stimussed Plus & 0,2 & $0,083 a b c$ & $1,067 \mathrm{bcd}$ & $1,233 b$ \\
\hline BR-12 Especial & 50,0 & 0,017c & $0,500 \mathrm{~cd}$ & $0,833 b$ \\
\hline BR-12 Especial & 100,0 & $0,017 c$ & $1,083 b c 1$ & $1,167 b$ \\
\hline FTE Cerrado & 50,0 & $0,067 a b c$ & $0,533 \mathrm{~cd}$ & $0,667 b$ \\
\hline FTE Cerrado & 100,0 & $0,117 a b$ & $1,400 a b$ & $1,333 b$ \\
\hline Zincogran & 50,0 & $0,000^{*} \mathrm{C}$ & $1,067 \mathrm{bcd}$ & $2,167 a$ \\
\hline Zincogran & 100,0 & $0,017 c$ & $2,100 a$ & $2,333 a$ \\
\hline Micronutri & 50,0 & $0,000 * c$ & $1,617 a b$ & $1,000 b$ \\
\hline Micronutri & 100,0 & $0,000 * \mathrm{c}$ & $1,767 a$ & $2,167 a$ \\
\hline $\mathrm{CdCl}_{2} \cdot \mathrm{H}_{2} \mathrm{O}$ & 25,0 & $0,033 b c$ & & \\
\hline $\mathrm{CdCl}_{2} \cdot \mathrm{H}_{2} \mathrm{O}$ & 50,0 & $0,133 a$ & & \\
\hline$\left(\mathrm{CH}_{3} \mathrm{COO}\right)_{2} \mathrm{~Pb} \cdot 3 \mathrm{H}_{2} \mathrm{O}$ & 25,0 & $1,200 \mathrm{bc}$ & & \\
\hline$\left(\mathrm{CH}_{3} \mathrm{COO}\right)_{2} \mathrm{~Pb} \cdot 3 \mathrm{H}_{2} \mathrm{O}$ & 50,0 & $1,767 a b$ & & \\
\hline $\mathrm{CrCl}_{3} \cdot 6 \mathrm{H}_{2} \mathrm{O}$ & 25,0 & $2,333 a$ & & \\
\hline $\mathrm{CrCl}_{3} \cdot 6 \mathrm{H}_{2} \mathrm{O}$ & 50,0 & $2,667 a$ & & \\
\hline
\end{tabular}

* Valor de concentração abaixo do limite de detecção do método.

** Médias seguidas de mesma letra não diferem significativamente pelo teste tukey $5 \%$.

\section{CONCLUSÃO}

Em relação às determinações de cádmio nas plantas de soja, os tratamentos que mais disponibilizaram o metal para as plantas foram o $\mathrm{CdCl}_{2} \cdot \mathrm{H}_{2} \mathrm{O}$ 2, FTE Cerrado 2, Stimussed Plus e FTE Cerrado 1. Considera-se concentrações de $0,5 \mathrm{mg} \mathrm{kg}^{-1}$ como valor de referência de cádmio em solos não contaminados e considera-se valores aceitáveis em tecido vegetal teores de 0,05 a $0,20 \mathrm{mg} \mathrm{kg}^{-1}$. Neste trabalho não foram detectados teores de cádmio preocupantes (18-19).

A maior liberação de chumbo para as plantas de soja ocorreu nos tratamentos Zincogran 2, Micronutri 1211 e 2, $\left(\mathrm{CH}_{3} \mathrm{COO}\right)_{2} \mathrm{~Pb} .3 \mathrm{H}_{2} \mathrm{O} 2$ e FTE Cerrado 2. Neste caso, verifica-se que o próprio solo disponibilizou o metal para as plantas testemunhas. Os teores deste metal considerados normais em tecido vegetal para diversas culturas estão na faixa de 0,1 a $1,0 \mathrm{mg} \mathrm{kg}^{-1}(18-19)$. 
Para o crômio, os tratamentos com $\mathrm{CrCl}_{3} \cdot 6 \mathrm{H}_{2} \mathrm{O}$ e Zincogran nas doses 1 e 2, foram os que mais liberaram o metal para as plantas. Novamente, a concentração natural do metal no solo disponibilizou altas concentrações para que as plantas apresentassem teores elevados do metal na parte aérea. Para este metal, consideram-se teores aceitáveis no tecido vegetal entre 0,1 a $0,5 \mathrm{mg} \mathrm{kg}^{-1}$ (18).

$\mathrm{O}$ aumento da dosagem das aplicações dos adubos e dos sais contendo os metais pesados tóxicos, aumentou a concentração dos metais nas plantas, em todos os casos.

A grande preocupação é que com a correção dos níveis de micronutrientes do solo utilizando estes tipos de adubos que além de disponibilizar micronutrientes essenciais e benéficos necessários ao bom desenvolvimento de diversas culturas, também disponibilizam metais pesados tóxicos $(\mathrm{Cd}, \mathrm{Pb}$ e
$\mathrm{Cr}$ ) indesejáveis à cadeia produtiva, causando uma contaminação cumulativa nos solos e transferindo boa parte destas concentrações aos animais e ao homem através da alimentação.

Demonstrou-se com este trabalho que principalmente no caso dos metais chumbo e crômio, as concentrações encontradas na parte aérea das plantas de soja já são consideradas preocupantes.

\section{AGRADECIMENTOS}

Agradecemos ao nosso amigo e colega Professor Pessoa ${ }^{+}$(in memorian) pela grande contribuição científica e principalmente pela sua grande capacidade em explicar o inexplicável.

\section{REFERÊNCIAS BILBLIOGRÁFICAS}

1 GONÇALVES JR., A. C.; LUCHESE, E. B.; LENZI, E. Avaliação da fitodisponibilidade de cádmio, chumbo e cromo, em soja cultivada em latossolo vermelho escuro tratado com fertilizantes comerciais. Química Nova, n. 2, vol. 23, p. 173-177. 2000.

2 BARCELÓ, J.; POSCHENRIEDER, C. Respuestas de las plantas a la contaminacion por metales pesados. Suelo y Planta, n.2, p.345. 1992

3 MALAVOLTA, E. Fertilizantes e seu impacto ambiental: metais pesados, mitos, mistificação e fatos. São Paulo, Produquímica: 1994; $153 \mathrm{p}$.

4 ALLOWAY, B. J. Heavy Metals in Soils. New York, 1990; $339 \mathrm{p}$.

5 KABATA-PENDIAS, A.; PENDIAS, H. Trace Elements in Soils and Plants. CRC PRESS; Boca Raton, 1984, 364 p.

6 AMARAL SOBRINHO, N. M. B.; COSTA L. M.; OLIVEIRAC.; VELLOSO, A. C. X. Metais pesados em alguns fertilizantes e corretivos. R. Bras. Ci. Solo, n. 16, p. 271, 1992.

7 LANZIANI, A. Avaliação da disponibilidade de zinco em alguns adubos comerciais. Maringá:1995. 55f. Dissertação de Mestrado (Mestrado em Química Aplicada - Agroquímica). Curso de Pós-Graduação em Química, Departamento de Química Universidade Estadual de Maringá.

8 BECKETT, P. H. T. Critical tissue concentrations as indicators of toxicity. Suelos Ecuatoriales, Bogotá, n. 2, p. 39, 1991

9 EMBRAPA. CNPS. Sistema Brasileiro de Classificação de Solos. Rio de Janeiro: EMBRAPA Solos, 1999. 412p.

10 SARRUGE, J.R.; HAAG, H.P. Análise Química em Plantas; Livroceres, Piracicaba, 1974, 56 p.

11 WELZ, B. Atomic Absorption Spectrometry; VCH; Weinheim, 1985, p 253.

12 FUNDAÇÃO INSTITUTO AGRONÔMICO DO PARANÁ - IAPAR. Análises Químicas de Solo: Parâmetros para Interpretação. Londrina:IAPAR, 1996, 48 p. (Circular 91).

13 ORGANIZAÇÃO DAS COOPERATIVAS DO ESTADO DO PARANÁ - OCEPAR/EMBRAPA-CNPSo. Recomendações Técnicas para a Cultura de Soja no Paraná 1994/95. Cascavel, 1994, 140 p. (Boletim Técnico 36).

14 PIMENTEL GOMES, F. Estatística Moderna na Pesquisa Agropecuária; Potafos, Piracicaba, 1984, p. 126.

15 MILLER, J. E. Uptake of cadmium by soybeans as influenced by soil cation exchange capacity, $\mathrm{pH}$ and available phosphorus. Journal of Environment Quality. Madison, n. 5, p.157, 1976.

$16 \mathrm{JOHN}, \mathrm{M}$. K. Cadmium adsorption maxima of soils as measured by the Langmuir isotherm. Canadian Journal of Soil Science. n. 52, p. 343, 1972

17 HASSETT, J. J. Capacity of selected Illinois soils to remove lead from aqueous solution. Communications in Soil Science and Plant Analysis. n. 5, p. 499. 1974.

18 BAKER, D. E. \& CHESNIN, L. Chemical monitoring of soils for environmental quality and animal and human health. Adv. Agron., New York, 27, 1975

19 KABATA-PENDIAS, A. \& PENDIAS, H. Trace elements in soils and plants. Boca Raton, Florida, CRC PRESS, 1984. 